\title{
DOCÊNCIA NO ENSINO SUPERIOR: NOVO CONTEXTO, NOVAS CONFIGURAÇÕES E REPRESENTAÇÕES
}

\section{TEACHING IN HIGHER EDUCATION: NEW CONTEXT, AND NEW CONFIGURATION REPRESENTATION}

\author{
SALES, Mônica Patrícia Silva \\ mps_28@hotmail.com \\ Faculdade de Filosofia Ciências e Letras de Caruaru \\ MACHADO, Laêda Bezerra \\ laeda01@gmail.com
}

Universidade Federal de Pernambuco

\begin{abstract}
RESUMO O artigo, resultado de pesquisa desenvolvida no curso de Mestrado em Educação da UFPE, analisa as representações sociais de docência no Ensino Superior construídas por estudantes de licenciaturas. Partimos do pressuposto de que o cenário de transformações e expansão da Educação Superior influencia na construção de representações sociais. Adotamos como referencial teóricometodológico a Teoria do Núcleo Central, proposta por Abric (2000). Apoiamo-nos ainda em Freire (1996), Masetto (1998; 2003), Tardif (2002), Zabalza (2004), dentre outros, que discutem a docência, entendendo-a como campo complexo e multidimensional. $O$ estudo, de natureza qualitativa, tomou como campo empírico uma Instituição de Ensino Superior privada e como participantes 194 estudantes de licenciaturas. O procedimento de coleta de dados utilizado foi a técnica de associação livre de palavras, cujos dados foram analisados com o auxílio do software EVOC, (VĖRGES-2003). Os dados revelaram que as representações sociais de docência no Ensino Superior construídas pelos estudantes das licenciaturas transcendem a mera instrução/transmissão de conteúdos específicos e se afiguram como algo amplo e global da ação do professor. Assim, os elementos que estruturam e organizam a representação social de docência oferecem indícios de uma ruptura com os modelos conservadores de ensino e de aprendizagem predominantes na cultura universitária, para representá-la como interlocução de aprendizagens, demandando mobilização socioafetiva, política e crítica.
\end{abstract}

PALAVRAS-CHAVE: Docência. Ensino Superior. Representações Sociais. Licenciaturas.

ABSTRACT The article is the result of research carried out in the course of master's degree in Education from UFPE, analyzes the social representations of teaching in higher education built by undergraduate students. We assumed that the scenario changes and expansion of higher education influences the construction of social 
representations. We adopted as a theoretical and methodological Central Nucleus Theory, proposed by Abric (2000). We rely also on Freire (1996), Masetto (1998, 2003), Tardif (2002), Zabalza (2004), among others, argue that teaching, understanding the field as complex and multidimensional. The study is qualitative, empirical field took as an institution of higher education and private participants as 194 undergraduate students. The data collection procedure used was the technique of free association of words and the data were analyzed with the aid of software EVOC, (Verges, 2003). The data revealed that social representations of teaching in higher education built by students of undergraduate transcend mere statement / transmission of specific content and seem like something broad and comprehensive teacher's action. Thus, the elements that structure and organize the representation of social teaching provide evidence of a break of conservative models of teaching and learning prevalent in university culture, to represent it as a dialogue of learning, requiring mobilization socioaffective, political and critical. KEYWORDS: Teaching. Higher Education. Social Representations. Degrees.

\section{INTRODUÇÃO}

A crescente expansão da oferta de Educação Superior em todo país e a demanda por profissionais qualificados para atuar nesse nível de ensino implicam a abertura de uma nova frente de pesquisa no sentido de serem compreendidas as alterações ocorridas e os seus significados para a própria docência.

Estudos sobre a docência e seus processos constitutivos são frequentes na literatura, contudo, muitos deles têm focado a docência na Educação Básica e poucos têm se debruçado em estudos acerca da docência no Ensino Superior, especialmente aquela exercida em cursos de licenciaturas, nos quais estão se formando os futuros professores.

Conforme apontam Zabalza (2004) e Masetto (1998), as mudanças no cenário universitário ocasionaram importantes transformações na docência, uma vez que a tradicional função do docente como transmissor de conhecimentos foi desprestigiada, dando espaço ao seu papel como mediador de conhecimentos. Diante deste cenário de mudanças, emerge a necessidade de pesquisas que busquem compreender suas implicações para a prática pedagógica e docente nas Instituições de Educação Superior e na formação dos futuros professores. Partimos do pressuposto de que este novo cenário pode estar abalando as representações sociais de docência.

Estas proposições nos levaram a investir neste campo buscando compreender as representações sociais de docência no Ensino Superior construídas 
por estudantes de licenciaturas. Durante dois anos pesquisamos, discutimos e analisamos o fenômeno no curso de Mestrado em Educação. Contudo, nos limites deste artigo, apresentaremos um recorte da pesquisa, no qual exploramos as análises dos dados coletados através da técnica de associação livre de palavras através da qual buscamos identificar a estrutura e organização das representações sociais de docência nesse nível de ensino.

Apoiamo-nos no referencial teórico-metodológico da Teoria das Representações Sociais que, por seu olhar psicossocial, permite compreender os processos simbólicos que ocorrem na interação educativa e que definem e determinam comportamentos e atitudes no grupo. Para Melo e Batista (2010, p. 61) "as representações sociais na área educacional fundamentam desde a compreensão de fenômenos macroscópicos como identidade cultural, até práticas concretas travadas no microcosmo da sala de aula na interação pedagógica e no trabalho docente". Diante do exposto, o campo das representações sociais se mostra promissor para os estudos que buscam desvelar as práticas institucionais e educativas que se realizam no espaço educacional e, portanto, pertinente e apropriado para investigar a docência em sua complexidade e multidimensionalidade. Pressupomos que à medida que os estudantes representam a docência e que têm contato com os docentes, possam refletir sobre estas práticas tomando-as como referências para sua própria prática e para a construção de sua identidade docente.

\section{A TEORIA DO NÚCLEO CENTRAL DAS REPRESENTAÇÕES SOCIAIS}

A Teoria do Núcleo Central, desenvolvida por Abric, em 1976, também chamada de Abordagem Estrutural é uma perspectiva complementar à grande teoria. O envolvimento com a prática experimental lhe confere o caráter de complementaridade à noção de representação social proposta por Moscovici em sua obra "La psycanalise: son image et son public". Abric (2000, p. 156) define a representação como "um conjunto organizado de opiniões, de atitudes, de crenças, e de informações referentes a um objeto ou a uma situação." Segundo o autor o que caracteriza uma representação é o seu compartilhamento por um grupo social. 
Trata-se de um saber prático da experiência vivida pelas pessoas, ou seja, de um conjunto de elementos que se organizam e se estruturam, constituindo um sistema sociocognitivo que dá significado à representação. $O$ surgimento desta teoria contribuiu para o refinamento conceitual, teórico e metodológico do estudo das representações sociais (SÁ, 1996; 1998). A tese principal defendida por Abric é de que toda representação social está organizada em torno de um sistema central e periférico que determina ao mesmo tempo sua significação e sua organização interna.

De acordo com Abric (2000) o núcleo central assume duas funções fundamentais: uma função geradora através da qual se cria, ou se transforma, o significado dos outros elementos constitutivos da representação e uma função organizadora que determina a natureza dos elos, unindo entre si os elementos da representação. O núcleo central é o elemento mais estável, coerente e rígido da representação, ele atribui significado à representação e é responsável pela unificação e estabilização dos elementos periféricos que se organizam em torno dela. Por resistir às mudanças, o núcleo assegura a continuidade em contextos móveis e evolutivos e define o consenso de um grupo. Portanto, toda modificação do núcleo central provoca uma transformação completa da representação. Trata-se de um subconjunto da representação, composto por elementos cuja ausência a desestruturaria ou the daria uma significação completamente diferente.

Os elementos periféricos, por sua vez, são móveis, flexíveis e sensíveis ao contexto imediato, eles se organizam em torno do núcleo central e são responsáveis pela atualização da representação à realidade do momento. Segundo Abric (2000, p.32) o sistema periférico também desempenha funções específicas, a saber: a função de concretização que resulta da ancoragem da representação à realidade; a função de regulação que promove a adaptação da representação às evoluções do contexto, constituindo o aspecto móvel e evolutivo da representação; a função de defesa que tem o papel de resistir à mudança, posto que sua transformação provocaria uma alteração completa na representação.

Deste modo, as representações sociais são ao mesmo tempo, estáveis e móveis, rígidas e flexíveis, consensuais e marcadas por diferenças individuais. Essas características aparentemente contraditórias explicam porque representações e práticas se engendram mutuamente, as quais circunscritas ao campo social 
empreendem sua dinâmica e complexidade, através de um duplo sistema que desempenha papeis específicos, mas complementares.

Neste artigo, discutiremos os elementos centrais e periféricos das representações sociais de docência no Ensino Superior construídas por estudantes de licenciatura.

Compreendemos que investigações que adotam a Teoria das Representações Sociais como fundamento teórico-metodológico são pertinentes para o campo da educação, uma vez que essas representações desempenham um papel fundamental na dinâmica das relações e práticas sociais e, por sua vez, a educação, enquanto prática social também se transforma acompanhando as mudanças da sociedade e exigindo novas configurações que fazem emergir novas representações sociais. Tal aporte teórico contribui para o entendimento dos referentes pessoais e sociais que produzem as representações sociais de forma articulada e dinâmica (GILLY, 2001).

\section{PROCEDIMENTOS METODOLÓGICOS}

A metodologia adotada para o estudo do qual decorre este texto é de natureza qualitativa, a qual enfatiza a necessidade de se penetrar no universo conceitual dos sujeitos (CHIZOTTI, 2001, p. 79). O fundamento teórico-metodológico da Teoria do Núcleo Central nos permite compreender a dimensão cognitivoestrutural que responde a uma visão funcional do mundo, permitindo ao indivíduo ou ao grupo dar um sentido às suas condutas e compreender a realidade através do seu próprio sistema de referências (ABRIC, 2000).

Neste trabalho utilizamos a Técnica de Associação Livre de Palavras como instrumento de coleta de dados. Este recurso permite o acesso a um material mais espontâneo, reduzindo as limitações das expressões discursivas e tem sido comumente utilizada nas pesquisas de representações sociais (OLIVEIRA et al., 2005). Consiste em levar os participantes a evocarem palavras ou expressões mediante apresentação de estímulo indutor. Nesse caso, o estímulo utilizado foi "Docência no Ensino Superior é". Aos estudantes foi solicitado que escrevessem as cinco primeiras palavras que lhes viessem imediatamente à mente em resposta à referida indução, foi solicitado ainda que hierarquizassem as palavras evocadas e 
justificassem a palavra considerada de maior importância. As evocações foram submetidas à tabulação e análise com o auxílio do software Ensemble de programmes permettant l'analyse dês evocations (EVOC), versão 2003, criado por Vergès. O EVOC calcula e informa a frequência (f) simples de ocorrência de cada palavra evocada, bem como a média das ordens médias de importância (OMI) (OLIVEIRA et. al., 2005), resultando em um quadro de quatro casas, onde localizamos o núcleo central e os elementos periféricos da representação social.

Elegemos como campo empírico de pesquisa uma instituição privada de Ensino Superior. A escolha se apoia na sua atuação consolidada no campo da formação de professores na região e, especialmente, no trabalho de articulação entre ensino, pesquisa e extensão, situação pouco comum nas práticas das instituições superiores privadas.

Participaram desse estudo, 194 estudantes dos cursos de licenciatura em Letras, História, Filosofia e Pedagogia, distribuídos em diferentes estágios de formação nos cursos. O grupo se constitui de estudantes entre 18 e 29 anos (82\%), com uma predominância de mulheres correspondendo a $60 \%$ do grupo pesquisado, $45 \%$ destes já atuam como professores/as ou exercem funções afins à educação, como auxiliar de biblioteca, auxiliar de professor/a e coordenador/a.

\subsection{A estrutura das representações sociais de docência no Ensino Superior construídas por estudantes de licenciaturas}

Conforme anunciamos, o software EVOC organiza as evocações tomando como base a frequência (f) de ocorrências das palavras evocadas e a ordem média de importância (OMI) gerando um quadro de quatro casas. As palavras que se destacam em relação à frequência (alta) e ordem de importância (mais próxima de 1) constituem a possível representação social pesquisada.

O quadro de quatro casas é constituído por palavras que estão distribuídas em quatro quadrantes, seguidas da média de frequência de aparição dos termos e das ordens médias de importância atribuídas a cada uma delas. Conforme Oliveira et al (2005) as palavras que se situam no quadrante superior esquerdo são, muito possivelmente, os elementos do núcleo central. Nele estão contidas as representações sociais; aquelas situadas no quadrante superior direito são os 
elementos da primeira periferia, estão mais próximos do núcleo central e indicam a possibilidade de já ter pertencido ou podem vir a pertencer a ele. No quadrante inferior esquerdo encontram-se os elementos da zona de contraste, estes são interlocutores, aqueles que embatem com o núcleo, tentam entrar ou permanecer nele, podem também representar a zona muda das representações sociais, os elementos latentes no discurso dos sujeitos. Já no quadrante inferior direito situamse os elementos da segunda periferia, eles estão mais distantes do núcleo e com menor possibilidade de vir a pertencer a ele.

Os critérios adotados pelo programa na distribuição dos termos nos quadrantes são a média de frequência das palavras $(F)$ e a ordem média de importância (OMI) atribuída às mesmas. Além disso, a frequência mínima de ocorrências das palavras arbitrada em igual ou superior a sete, exclui da análise aquelas cujos valores sejam abaixo de sete. Segundo Oliveira et al. (2005), os termos que atendam, ao mesmo tempo, aos critérios de frequência e ordem prioritárias de evocação teriam maior importância no esquema cognitivo do sujeito e, provavelmente, pertenceriam ao núcleo central. Desta forma, quanto maior a frequência e mais baixa a OMI, concomitantemente, mais importante é a palavra e maior sua possibilidade de integrar o núcleo central.

Destacamos que a partir das justificativas produzidas pelo grupo, as palavras consideradas mais importantes foram organizadas e analisadas em confronto com os resultados do quadro de quatro casas, visando desvendar os sentidos e significados atribuídos pelos estudantes à docência no Ensino Superior, para além do conteúdo das representações buscamos compreender sua estrutura, como veremos no Quadro $1^{1}$, a seguir:

QUADRO 1: Estrutura das Representações Sociais de Docência no Ensino Superior dos estudantes de licenciaturas

\begin{tabular}{|c|c|c|c|c|c|}
\hline \multicolumn{2}{|c|}{$\mathrm{F}>=7 / \mathrm{OMI}<2,5$} & \multicolumn{3}{c|}{$\mathrm{F}>=7 /$ OMI $>2,5$} \\
\hline & $\mathrm{F}$ & $\mathrm{OMI}$ & $\mathrm{F}$ & $\mathrm{OMI}$ \\
\hline
\end{tabular}

\footnotetext{
${ }^{1}$ Esclarecemos que a frequência $(F)$ mínima de aparição dos termos foi arbitrada em $>$ ou $=7$, o que significa que os termos que tiveram frequência inferior a 7 foram desconsiderados da análise. Esclarecemos ainda que a ordem média de importância (OMI) obteve um escore de 2,5, ou seja, no quadro de quatro casas o software considerou apenas os termos que foram hierarquicamente mais importantes para os participantes da pesquisa.
} 


\begin{tabular}{|c|c|c|c|c|c|}
\hline $\begin{array}{l}\text { Aprendizagem } \\
\text { Competência } \\
\text { Compromisso } \\
\text { Conhecimento } \\
\text { Dedicação } \\
\text { Ética } \\
\text { Respeito } \\
\text { Responsabilidade }\end{array}$ & $\begin{array}{l}23 \\
29 \\
40 \\
26 \\
38 \\
11 \\
13 \\
50\end{array}$ & $\begin{array}{l}2,261 \\
1,655 \\
2,275 \\
1,731 \\
2,395 \\
1,818 \\
2,308 \\
2,300\end{array}$ & $\begin{array}{l}\text { Construção } \\
\text { Experiência } \\
\text { Formação } \\
\text { Importante } \\
\text { Sabedoria }\end{array}$ & $\begin{array}{l}10 \\
11 \\
17 \\
10 \\
12\end{array}$ & $\begin{array}{l}2,700 \\
2,636 \\
2,588 \\
3,300 \\
2,500\end{array}$ \\
\hline \multicolumn{3}{|c|}{$F>=7 /$ OMI $<2,5$} & \multicolumn{3}{|c|}{$F>=7 / O M I>2,5$} \\
\hline & $\mathbf{F}$ & OMI & & $F$ & OMI \\
\hline $\begin{array}{l}\text { Amor } \\
\text { Capacidade } \\
\text { Criticidade } \\
\text { Desafio } \\
\text { Ensinar } \\
\text { Inteligência }\end{array}$ & $\begin{array}{l}9 \\
8 \\
8 \\
9 \\
7 \\
7\end{array}$ & $\begin{array}{l}2,222 \\
2,000 \\
1,875 \\
2,444 \\
2,429 \\
2,286\end{array}$ & $\begin{array}{l}\text { Conquista } \\
\text { Interação } \\
\text { Profissionalismo } \\
\text { Reflexão }\end{array}$ & $\begin{array}{l}7 \\
7 \\
7 \\
7\end{array}$ & $\begin{array}{l}2,714 \\
3,714 \\
2,714 \\
2,714\end{array}$ \\
\hline
\end{tabular}

\subsection{Docência no Ensino Superior: uma prática profissional, social e afetiva}

Como podemos observar no quadro acima, no possível núcleo central da representação, localizamos as palavras "aprendizagem", "competência", "compromisso", "conhecimento", "dedicação", "respeito", "responsabilidade" e "ética". Estas palavras foram as mais frequentemente evocadas e prontamente indicadas como as mais importantes pelo grupo de estudantes. Conforme Abric (2000, p. 31) os elementos do núcleo central dão significado à representação, destacando-se por sua dimensão quantitativa e qualitativa.

Inferimos que as palavras "competência" e "conhecimento" correspondem a elementos de ordem profissional. Já as palavras "aprendizagem", "respeito" e "ética" configuram-se como elementos de ordem social e sugerem troca de conhecimentos na relação com o outro, além de práticas pautadas no respeito ao saber do educando e no testemunho ético. Os termos "compromisso", "dedicação" e "responsabilidade", estão ligados a elementos de ordem pessoal e afetiva, referemse aos empreendimentos pessoais e socioprofissionais dos docentes.

Sobre as palavras "competência" e "conhecimento", os estudantes afirmam:

O docente tem que ser competente para exercer o cargo onde se esforçou para estar lá, pois se ele não tem competência, não formará uma turma de qualidade e como consequência teremos professores de péssima qualidade nas salas de aula. $(P 46)^{2}$

\footnotetext{
${ }^{2}$ Neste texto os participantes são identificados da seguinte maneira: a letra maiúscula "P" seguida de um número, que corresponde ao protocolo de ordem de aplicação da associação livre.
} 
A palavra que ganha destaque, na minha visão, referente a docência no Ensino Superior, é a competência. Diante dos atuais profissionais no mercado de trabalho, ganha destaque sem dúvida aquele indivíduo que seja adepto de competência para exercer sua profissão com responsabilidade. Afinal, na docência estamos trabalhando com a formação intelectual do aluno. (P85)

Nas justificativas dos estudantes ${ }^{3}$ verificamos que a docência está associada ao domínio de conhecimentos teóricos e práticos, reflexo da estrutura organizativa do Ensino Superior que durante muito tempo considerava este aspecto como requisito principal para atuação na docência nesse nível de ensino. Conforme Masetto (1998) essa competência é compreendida como o domínio de conhecimentos e experiência profissional do professor no campo em que atua.

Observamos ainda, nos trechos das justificativas acima apresentadas, que os estudantes relacionam a competência docente com a qualidade do ensino. As referências dos participantes ao termo qualidade não conota uma posição exclusivamente mercadológica ao termo, mas sugere um entendimento coletivo de que a qualidade deve ser sempre perseguida, pois é algo desejável e bom para a profissão.

A presença do elemento "competência" no provável núcleo central indica que ele é um forte orientador das representações sociais da docência no Ensino Superior construídas pelos estudantes, para os quais a atividade requer competência que implica em qualidade, ou seja, os termos estão intimamente relacionados e imbricados. Trata-se de um elemento que foi indicado em primeira ordem de importância, com OMI de $(1,655)$ e que, por sua localização privilegiada no núcleo central, contribui para garantir as funções geradora e organizadora da representação, ou seja, atribui sentido, dá unidade e estabilidade a essa representação.

Rios (2006, p. 89) discutindo o termo competência, nos ajuda na sua compreensão quando afirma que:

[...] para dizer que um professor é competente, devo levar em conta a dimensão técnica - ele deve ter domínio dos conteúdos de sua área específica de conhecimento e de recursos para socializar esse conhecimento; a dimensão política - ele deve definir finalidades para sua ação e comprometer-se em caminhar para alcançá-las; e a ética, elemento

\footnotetext{
${ }^{3}$ As justificativas dos estudantes foram transcritas tal qual sua elaboração preservando a pontuação e destaques dados às expressões. Houve apenas a correção às palavras que apresentaram erros ortográficos.
} 
mediador - ele deve assumir continuamente uma atitude crítica, que indaga sobre o fundamento e o sentido da definição dos conteúdos, dos métodos, dos objetivos, tendo como referência a afirmação dos direitos, do bem comum.

Podemos perceber que a autora qualifica a competência como um conjunto de propriedades de caráter técnico, político e ético que o docente vai adquirindo ao longo de sua formação e experiência como elementos historicamente situados, construídos pelos sujeitos em sua práxis que se refere a um fazer que demanda saberes e implica em posicionamento político. Para além de uma cobrança externa do mercado de trabalho, que atribui à qualidade um sentido de produtividade, eficácia e eficiência. Na fala a seguir, podemos verificar a presença desses elementos como norteadores do exercício docente no Ensino Superior.

A competência é um dos principais eixos que melhor conceitua a docência no Ensino Superior. Entre as suas atribuições o docente que se mostra competente no que leciona, passa mais confiança e credibilidade. (P54)

Como podemos perceber a competência docente é também compreendida pelos estudantes como um elemento que transmite segurança, confiança e oferece credibilidade ao professor perante os alunos, a qual seria uma condição fundamental para fazer bem, exercer bem o seu papel. O termo competência pode assumir diferentes sentidos para cada teórico, pois estamos diante de um termo polissêmico, que sugere diferentes interpretações, mas que está associado, sobretudo, à capacidade de fazer bem determinada atividade (RIOS, 2006, 2011), em nosso caso a docência no Ensino Superior.

Sobre a palavra "conhecimento", consideramos que se trata de um termo da área exigido para todas as profissões, e no caso da docência faz-se necessário além do conhecimento específico, o pedagógico, ou seja, conforme apontaram os estudantes, além de conhecer é preciso que o professor seja capaz de criar meios que facilitem a apropriação do conhecimento. Considerando as questões que foram discutidas até o momento, depreendemos que a docência no Ensino Superior demanda um perfil de profissional com amplo domínio do conhecimento científico e competência pedagógica.

No que se refere ao elemento "aprendizagem" reflete para nós o reconhecimento de que ensinar não é transferir conhecimentos, mas pôr-se em 
relação com outro, consigo mesmo e com o mundo, aprendendo e ensinando (FREIRE, 1996). Aprender constitui-se elemento fundamental para o enriquecimento do conhecimento do homem que se insere na condição de sujeito inacabado. Vejamos:

Para mim a palavra mais importante é aprendizagem, uma vez que o docente nunca poderá ficar parado em seus estudos, ele sempre irá necessitar de novos conhecimentos que podem ser adquiridos com os discentes em sala de aula. (P75)

[...] a aprendizagem deve ser sempre de professor para aluno e vice-versa. (P135)

Como podemos perceber, para os estudantes que participaram desta pesquisa, o aprender é representado como condição humana e científica, uma relação na qual professores e alunos interagem. Nesse contexto, destacamos as contribuições de Freire (1996) para quem ensinar inexiste sem aprender e viceversa. Segundo o autor, quem ensina aprende ao ensinar e quem aprende ensina ao aprender. Para os estudantes ouvidos nesta pesquisa, a aprendizagem não lhes é exclusiva, mas compartilhada entre eles e o professor, aproximando-se das proposições de Freire. Também Matos (2001, p. 50) refere-se à aprendizagem como algo que tem sua marca na relação interpessoal e no crescimento humano. Consideramos que a formação pedagógica a que os estudantes têm acesso pode estar exercendo um papel significativo para evocação da palavra aprendizagem com esse significado.

O termo "respeito", mesmo localizado no provável núcleo central, foi pouco indicado como mais importante pelos estudantes, ao se referirem à docência no Ensino Superior. Contudo, as considerações feitas para com o termo aprendizagem, nos levam a inferir que esse termo foi utilizado para ressaltar os saberes do próprio educando e sua condição de sujeito que aprende e ao mesmo tempo, também, ensina.

Respeito em tudo que fazemos. Torna-se um trabalhador eficaz, o profissional que é hábil em reconhecer o limite do indivíduo, enquanto ser humano, e leva em conta, as condições psicológicas, afetivas, emocionais, entre outras, respeitando-o em primeiro lugar enquanto ser social. (P87) 
Nesse sentido, o respeito é considerado imprescindível à docência, respeito que compreende de maneira ampla o olhar para o outro, suas peculiaridades e seu conhecimento. De maneira estrita podemos dizer que o respeito é condição para se relacionar e conviver socialmente, respeitando a diversidade étnica, racial, religiosa, de orientação sexual e de gênero dos indivíduos. O trecho que se segue ilustra a importância do respeito na maneira de avaliar e de reconhecer os saberes dos estudantes.

Entre outros, o respeito é fundamental, principalmente na forma de avaliar o aluno (a), respeitando o conhecimento que já tem e levá-lo a despertar e buscar outros. (P08)

A avaliação em todos os níveis de ensino costuma ser usada como averiguação do que foi assimilado do curso, mediante provas tradicionais e notas classificatórias, nas quais os estudantes são levados a reproduzir as informações recebidas. Em geral a avaliação não tem sido objeto de reflexão crítica da própria prática docente, também não se constitui como um momento de aprendizagem para ambos, mas se resume a mensuração da aprendizagem dos estudantes.

No que se refere à palavra "ética", esta se destaca com uma das mais baixas OMI $(1,818)$, o que significa dizer que foi uma das palavras consideradas mais importantes pelos estudantes ao se referirem à docência no Ensino Superior. Eles afirmaram:

Ética profissional - faz com que o profissional saiba aceitar a diversidade e a cultura dos seus educandos. (P184)

Em qualquer lugar ou função que nos seja confiada, temos que ser pessoas éticas, compromissadas conosco e com toda a comunidade para a construção de um mundo cada vez melhor, com nossa doação e nosso compromisso com a vida. (P66)

Ética e respeito são valores morais intrinsecamente relacionados, pois revelam condutas humanas esperadas, no caso da docência, uma atividade própria do ser humano, de relações e interações, a dimensão ética exprime os princípios e normas que regem o seu exercício e as relações que se estabelecem no ambiente educacional. Rios (2011, p. 95) fala de uma possível "alienação de caráter ético, que significa o não reconhecimento do outro, o desrespeito à diversidade e, portanto, a impossibilidade de se instalar o diálogo". Como podemos observar, a dimensão ética 
se insere no campo da subjetividade como a forma de agir e conviver em relação aos outros, mas pode significar ainda no campo da coletividade as relações com a instituição e a sociedade, repercutindo na profissionalização do ensino, através da constituição de um código de ética profissional, algo de que ainda não dispomos na profissão docente. (VEIGA; ARAÚJO; KAPUZINIAK, 2005).

Conforme já mencionamos, a ética diz respeito a condutas esperadas, respaldamo-nos nos argumentos compartilhados dos estudantes que reclamam a necessidade de coerência entre o discurso e a prática de seus professores, argumentos estes que conotam indícios de que o discurso pode contradizer as práticas. Como estamos trabalhando com futuros docentes, o testemunho ético dos seus professores apresenta-se como modelo para sua formação.

É necessário que todo docente tenha ética profissional mediante o seu comportamento para com os discentes. (P84)

Para uma boa docência é primordial que o educador tenha ética em suas palavras e no que repassa aos demais para que não haja uma contradição em suas concepções e práticas. (P116)

Conforme os estudantes, é primordial que o docente seja ético, que suas atitudes e condutas sejam baseadas na ética como princípio orientador do seu discurso e prática. Essas assertivas nos inclinam a compreender a ética como uma fundamentação ontológica, uma vez que as ações humanas sempre se desenvolveram no âmbito das relações com os outros, com o coletivo social.

Para Abric (2000) a representação é um sistema de pré-codificação da realidade porque determina um conjunto de antecipações e expectativas, sendo assim, representar é significar, dar sentido às condutas de um grupo e compreender a realidade na qual está inserido. Desta forma, pressupomos que as representações de docência no Ensino Superior centradas na dimensão ética determinam o modo de interação/relação desses estudantes com seus professores e orientam suas práticas enquanto futuros profissionais.

No que se refere à palavra "compromisso", trata-se de um termo que obteve a segunda maior frequência de ocorrência (40) pelos participantes. Percebemos, pelas justificativas dadas, que compromisso significa trabalho de boa qualidade por parte dos professores. Os estudantes afirmam: 
Comprometimento - eu a considero importante pelo fato de ser o elemento chave para uma educação de qualidade, quando se há comprometimento corremos atrás do que consideramos importante para as nossas realizações. (P24)

Ser comprometido porque não basta apenas ensinar por ensinar, a educação e o ato de educar exige de cada um de nós comprometimento com o que fazemos. (P29)

Nesta perspectiva, o compromisso assume uma dimensão profissional e política, na qual o docente, ciente de sua tarefa educativa, prima pela qualidade do seu trabalho e revela sua opção política de engajamento com a educação de maneira crítica ou acrítica, autoritária ou progressista, dialógica ou antidialógica. Portanto, se me comprometo ou não com o trabalho que realizo, acabo por revelar minhas opções políticas na forma como compreendo e significo minha atuação profissional. Uma característica comum desses estudantes é o estágio de formação, ambos estão no $1^{\circ}$ período do curso. Entendemos que por ainda não terem uma vivência mais consolidada no curso, outros suportes, como por exemplo, o midiático pode estar contribuindo para a construção da representação social de docência que se expressa como compromisso com a sociedade e a formação dos cidadãos. 0 compromisso ainda assume uma dimensão afetiva e social na medida em que os estudantes associam o termo ao amor e à dedicação ou mesmo à responsabilidade docente em relação aos estudantes.

O compromisso é a base para se fazer o seu trabalho com amor e dedicação. (P172)

Compromisso, pois se existe compromisso estará motivando os alunos para assim se envolverem nas aulas e até mesmo seguir o exemplo do professor, quando escolher a profissão que vão seguir. (P139)

A segunda justificativa, de uma estudante do curso de história, que ainda não atua como docente, destaca a importância da atuação compromissada de seus professores, como inspiração ou motivação para seu ingresso no campo profissional. As justificativas acima encontram respaldo no que afirma Freire (1996, p. 96) sobre o comprometimento do professor ao ensinar:

Não posso ser professor sem me pôr diante dos alunos, sem revelar com facilidade ou relutância minha maneira de ser, de pensar politicamente. Não posso escapar a apreciação dos alunos. E a maneira como eles me percebem tem importância capital para o meu desempenho. Daí então que 
uma de minhas preocupações centrais deva ser a de procurar a aproximação cada vez maior entre o que digo e o que faço, entre o que pareço ser e o que realmente estou sendo.

Frente às justificativas para o termo compromisso aqui postas, podemos inferir que não só os professores avaliam os estudantes, mas também os docentes são avaliados constantemente em suas práticas por seus alunos. Também nos parece evidente que o docente não é apenas alguém que transmite um conhecimento produzido por outros, mas um sujeito histórico, social e político. Freire nos ajuda a compreender outra dimensão do compromisso, ou seja, de como o aluno entende a atuação do professor e sua importância para o desempenho docente.

A palavra "dedicação" frequentemente evocada pelos estudantes (38) compreende o esforço empreendido pelo docente do Ensino Superior para alcançar os objetivos, o que muitas vezes significa abrir mão de estar com a família e os amigos, de ter momentos de lazer, para dedicar-se aos estudos, pesquisa e formação permanente. Para os estudantes, a dedicação não está relacionada a afeto ou veneração ao trabalho, mas refere-se ao esforço e empenho do profissional em suas atividades docentes. É o que apontam as justificativas a seguir:

Dedicação, porque sem ela não conseguimos alcançar nenhum objetivo. (P174)

Quando nos dedicamos àquilo que fazemos, em qualquer área de trabalho ou na docência, fazemos as coisas com perfeição, pois ao nos dedicarmos automaticamente seremos transparentes, responsáveis, amáveis e abnegaremos qualquer coisa em prol daquilo que nos realiza. (P37)

Na perspectiva dos estudantes, dedicar-se é fundamental para o alcance dos objetivos, bem como para fazer bem feito o nosso trabalho, seja qual for a área de atuação profissional. Os estudantes têm clareza de que o esforço e a dedicação ao trabalho podem implicar muitas vezes em abdicar de algo em função dos objetivos que se almeja alcançar.

Sobre o termo "responsabilidade" evidenciamos que foi o termo de maior frequência (50) do núcleo central e com OMI (2,300), foi o mais recorrente, mas sua OMI não foi das mais baixas. Porém, sua forte frequência indica que o exercício docente no Ensino Superior demanda responsabilidades. Afirmam os estudantes: 
Em qualquer área é necessário ser um profissional responsável e não poderia se esperar algo diferente do professor que é o aporte para todos os profissionais. (P176)

Responsabilidade, pois devemos ser responsáveis com os nossos compromissos e nos esforçar para realizarmos os deveres de forma adequada. Devemos ser responsáveis pelos nossos atos e atitudes. (P11)

Segundo o dicionário Amora (2008, p. 634), responsabilidade significa "qualidade de ser responsável, obrigação de responder por certos atos e efeitos". E é justamente nesse sentido que o termo responsabilidade foi descrito pelos estudantes. Responsabilidade com o trabalho, com as práticas, com os discursos, atos, atitudes, e de um modo geral por todos os deveres próprios da docência. Assumir responsabilidades pelo trabalho que se desempenha é tomado como primordial para o seu êxito e construção de boas relações no ambiente em que se está inserido.

A responsabilidade também foi colocada como algo a ser ensinado através do exemplo, ou, parafraseando Freire, através do testemunho, sobretudo o do fazer, ou seja, a prática que realizo implica de forma direta e imediata na forma como os alunos entendem e significam minha atuação e implica em sua atuação futura. Ressaltamos, pois, conforme Abric (2000), que "a representação social é um guia para a ação". O nosso pressuposto de que a forma como o aluno representa a docência implica em sua prática profissional futura se confirma no momento em que os estudantes destacam a influência das práticas de seus professores para sua própria prática, como atestam as justificativas para o termo responsabilidade, a seguir:

A docência deve ser encarada com responsabilidade, pois o professor tem em suas mãos o poder de influenciar na formação dos futuros cidadãos. (P144)

No caso do professor do Ensino Superior eu acho que ele tem mais responsabilidade do que um professor de ensino médio, porque ele está formando profissionais. (P113)

A representação social que os estudantes compartilham da docência no Ensino Superior concorre para o desempenho e atuação profissional, pois o fazer 
docente de seus professores é tomado como modelo de referência enquanto futuros profissionais.

Assim, o núcleo central que sustenta as representações sociais de docência no Ensino Superior dos estudantes tem sua estrutura marcada por elementos funcionais como conhecimento e competência, que se constituem em elementos importantes para realização da tarefa que compete ao docente; elementos normativos de ordem socioafetiva, política e ideológica, representados pelas palavras compromisso, ética, responsabilidade e dedicação.

No conjunto de elementos que compõem o núcleo central da representação de docência, identificamos uma valorização da dimensão profissional, que reconhece a docência como prática social intencional, inserida no debate recente em que a dimensão estritamente técnica ou meramente instrucional não ganha relevo, mas incorre sobre aspectos de ordem profissional, social e afetiva. Esses aspectos focalizam a docência como uma prática social comprometida com a aprendizagem dos estudantes, em constante busca por formação e aperfeiçoamento de competências para atuar nesse nível de ensino.

Conforme já pontuamos, a representação social é composta por um sistema central e um sistema periférico que desempenham funções específicas, mas complementares. Deste modo, apresentamos na sequência deste artigo os elementos periféricos que organizam e conferem sentido e significado às representações de docência no Ensino Superior construídas pelos estudantes das licenciaturas.

\subsection{A construção dos sentidos e significados atribuídos à docência: o olhar sobre a periferia das representações em foco}

No quadro 1, apresentado anteriormente, localizamos no quadrante superior esquerdo a $1^{\text {a }}$ periferia, nela são encontrados os elementos periféricos mais importantes. Esses elementos estão mais próximos do núcleo central e, conforme a lógica do EVOC, poderão vir a pertencer a esse núcleo ou em algum momento dele já foram parte. Neste quadrante, localizamos as palavras "construção", "experiência", "formação", "importante" e "sabedoria". Optamos por trabalhar com as palavras 
agrupadas segundo a significação próxima. Essa opção se deve em função da organização didática e objetiva desse conteúdo representacional.

Assim, discutiremos inicialmente os sentidos atribuídos às palavras "formação", "experiência" e "sabedoria" que constituem um conjunto de elementos relacionados à dimensão profissional e pessoal da docência. Depois abordaremos as palavras "construção" e "importante" que correspondem à ação de ensinar como forma de mediação e interações humanas.

A palavra "formação" é expressa como verbo pronominal que significa ir-se desenvolvendo uma pessoa, assumindo um sentido processual. Os estudantes apontam para a função social do docente, como veremos a seguir:

\begin{abstract}
A docência no Ensino Superior tem uma responsabilidade maior em formar os discentes, pois daqui sairá o futuro da nação, pessoas maduras, sociais e responsáveis na construção de uma sociedade melhor. Mas a formação é, repito, permanente. (P60)
\end{abstract}

A atividade docente no Ensino Superior é antes de tudo formadora, nesta perspectiva e tendo em vista as exigências da modernidade esta tem como compromisso formar e capacitar o discente ao exercício eficiente, críticoreflexivo e transformador quando ocupar a posição de docente. (P02)

Essas falas são reveladoras de uma visão de incompletude do ser humano, em constante aprendizagem e formação. Elas revelam ainda o valor atribuído à função social da docência para a formação do cidadão crítico e reflexivo, capaz de transformar a sociedade. Além de destacar a importância da formação pessoal, social e profissional dos indivíduos.

No que diz respeito às palavras "experiência" e "sabedoria" percebemos que os sentidos a elas atribuídos são similares, pois compreendem a natureza dos conhecimentos adquiridos pelos docentes ao longo de sua vida pessoal e profissional, conforme veremos a seguir:

O professor principalmente o do Ensino Superior, precisa ter um amplo conhecimento e uma boa experiência de sala de aula, pois o mesmo é visto por todos como um espelho, logo se ele não tem experiência não saberá passar o conteúdo de ensino de maneira prática e eficaz. ...(P90)

Sabedoria, porque envolve todos os conhecimentos teóricos, e partes importantes da vida das pessoas que possuem uma sabedoria, que ultrapassa os conteúdos. (P132) 
Os estudantes destacam a sabedoria e a experiência como fonte de conhecimentos que orientam as práticas docentes de seus professores e referenciam práticas docentes futuras, uma vez que consideram a atuação dos professores como referências para a aprendizagem da docência. Destacamos, ainda, que a sabedoria ultrapassa o conhecimento dos conteúdos, sendo compreendida como o conjunto de saberes aos quais os professores tiveram acesso em suas experiências cotidianas.

No que se refere à questão da experiência, Behrens (1998, p. 60) afirma que "alguns pedagogos, professores universitários, nunca exerceram as funções que apresentam aos seus alunos. Falam em teoria sobre uma prática que nunca experienciaram". Supomos que este seja um conflito vivenciado por muitos professores que atuam em cursos de formação de professores para a Educação Básica. A esse respeito, Cunha, Brito e Cicilline (2006), investigando a formação para o Ensino Superior, identificaram que os professores estão conscientes sobre a situação de despreparo, porém apesar de reconhecerem essa condição muitos acabam por reproduzir práticas de antigos professores consideradas consagradas.

Os termos "importante" e "construção" expressam a função docente enquanto processo educativo de construção de conhecimentos, a docência como a ação de ensinar, porém ensinar de forma crítica, dialógica e aprender continuamente à medida que ensina.

O ser e o fazer docente no Ensino Superior deve ser pautado na construção de saberes em que deve primar pela discussão e diálogo, tanto referente à prática como a teoria em uma constante ressignificação do ser e do fazer docente. Portanto, a docência no Ensino Superior é ampliar as construções dos saberes, sem, no entanto, absolutizá-las. (P133)

Haja vista que o processo da docência visa não somente o docente, mas também o discente e tudo o que se relaciona com o processo de ensinoaprendizagem, ela se constitui como processo contínuo de construção de conhecimentos, tanto do professor universitário, quanto dos alunos que em alguns casos visam também essa docência que necessita de especialização e trabalho para se efetivar. (P49)

Para nós, as duas falas são reveladoras de uma concepção crítica da docência, que possivelmente foi se ancorando à representação construída pelos estudantes durante seu período de formação, pois são estudantes que se encontram no estágio intermediário e final dos seus cursos. Em suas falas trazem a importância 
do diálogo e das discussões como promotoras da ressignificação do ser e do fazer docente, situando o seu exercício como uma prática social, que se realiza na troca com outro, nas interações sociais entre discentes e docentes. Nesse sentido, percebemos o conceito de docência como atividade de mediação dirigida para fins educativos, como ressignificação entre teoria e prática, do ser e do fazer docente, articulação dialógica entre professores e alunos, aspectos estes bastante pontuados por Tardif e Lessard (2009).

Como observamos, os elementos situados na "1a periferia" expressam a importância da formação, dos saberes e da experiência, destacam a docência como profissão que demanda aprendizagem de saberes específicos. Eles reforçam a importância social da profissão de uma maneira geral e para a mediação da aprendizagem dos estudantes de maneira particular.

No quadrante inferior esquerdo, do Quadro 1, encontramos as palavras "amor", "capacidade", "criticidade", "desafio", "ensinar" e "inteligência”, compondo a chamada zona de contraste da representação social. O conjunto de elementos situados nesse quadrante está representado por palavras que se embatem com o núcleo central, ou seja, eles se embatem com uma representação de docência vinculada ao profissional.

Os termos "amor" e "desafio" expressam as condições para o exercício profissional, ou seja, que é preciso gostar do que faz para ser dedicado, comprometido e competente e de que é grande o desafio para atuar no Ensino Superior.

O amor, pois, se não tiver amor naquilo que faz de nada adianta as outras escolhas. Impedindo assim de ser um profissional de qualidade e competência naquilo que faz. (P39 $\left.F P 1^{\circ} \mathrm{O}\right)$

O amor porque ele abrange todas as outras características, sem o amor pelo que faz não tem como o ensino ter competência, dedicação, compromisso com o que faz, enfim, dar-se a fim de ajudar o outro a adquirir conhecimentos, melhorar suas relações, apenas no objetivo de ver o outro crescer humanamente. (P121)

Amor e doação, e, é preciso doar-se para formação de si mesmo e do próximo. (P160)

O amor ao qual se referem os participantes da pesquisa não se vincula à maternagem como vemos em pesquisas que focam a docência na Educação Básica, 
mas designa o gosto, gostar é um requisito imprescindível para o exercício docente. O amor a que se referem os estudantes desta pesquisa aproxima-se do entendimento de Freire, de que, quem não ama, não é capaz de compreender o outro, de respeitá-lo e de educá-lo. Os sentidos de docência focado no "amor" identificado nesta pesquisa diferem dos apontados por Machado e Santos (2011) que evidenciaram representações sociais do ser professor construídas por professoras da Educação Básica, centradas em vocação, gostar de criança e maternagem, agregados aos elementos dedicação, compromisso, amor e doação, compondo esse campo representacional.

Sobre as palavras "capacidade", "ensinar" e "inteligência" vimos, nas justificativas dos estudantes, que para exercer a docência é necessário ser capaz, ou seja, ter inteligência, ser capaz de ensinar, de tornar transmissível o conhecimento adquirido. Capacidade implica em superar os desafios, respondendo às exigências por formação especializada.

A capacidade diz respeito à forma com a qual o profissional se supera e se eleva para responder às exigências que a ele são impostas. A capacidade é também o conhecimento que o profissional adquiriu em sua trajetória de estudo. (P35)

Como vimos, a capacidade e a inteligência aparecem quase como sinônimas, e, como próprio das cognições periféricas, compõem o campo das descrições e das expectativas em relação ao fenômeno representado. Os termos refletem as expectativas dos estudantes em relação aos seus docentes. Considerando que estes elementos estão localizados na zona de contraste da representação e se configuram como elementos que destoam do núcleo central, entendemos que as palavras "capacidade", "ensinar" e "inteligência" identificam-se com uma perspectiva mais tradicional e conservadora do ensino na universidade, enquanto que no núcleo central identificamos elementos que se voltam para uma perspectiva socioprofissional que reconhece e valoriza a profissionalização do ensino.

O termo "criticidade" foi trabalhado isoladamente, por ser um elemento com a mais baixa OMI $(1,875)$ localizado na zona de contraste. O quantitativo indica que foi o termo considerado mais importante em grau de hierarquização. O senso crítico é o elemento novo que se ancora à representação social de docência, algo recente na literatura. A criticidade é vista como possibilidade de superação de qualquer forma 
de alienação ou de ingenuidade, contemplando uma visão ampla e reflexiva sobre a escola como espaço de formação social, política e ideológica.

Destacamos que igualmente importante é desenvolver essa criticidade nos estudantes, o que só é possível se o docente possibilitar ao discente a superação da ingenuidade intelectual. Recorremos a Masetto (2003, p. 53) para quem desenvolver uma reflexão crítica no adulto é fundamental. O autor defende que o professor deve permitir aos discentes "conhecer diferentes teorias e pontos de vista, discutir alternativas para o exercício de sua profissão, dialogar sobre os valores embutidos nas soluções técnicas apresentadas, analisar as perspectivas do mundo social e político". Para este autor, o docente do Ensino Superior tem como uma de suas funções primeiras o desenvolvimento da capacidade crítica nos estudantes, o que implica que o docente seja um sujeito crítico, capaz de elucidar diferentes questões acerca de um mesmo fenômeno e que possibilite a análise da sociedade e do exercício de sua profissão.

Os elementos presentes na zona de contraste, conforme discutimos, incidem sobre a capacidade intelectual, formativa e crítica do professor para o exercício docente. Além de destacar os desafios da profissão e o amor pelo que faz. Esses elementos atualizam a representação, ancorando-a na realidade, ao mesmo tempo em que se embatem com o núcleo central, tentando fazer parte dele.

Ainda no quadro 1, antes apresentado, localizamos no quadrante inferior direito a $2^{a}$ periferia. Nela estão localizadas as palavras "conquista", "interação", "profissionalismo" e "reflexão". Estes elementos estão mais distantes da representação social de docência e são menos prováveis de vir a se tornar do núcleo central.

O elemento "conquista", assim como os elementos "importante" e "desafio", enfatiza o status do magistério superior. Respaldamos nosso argumento em Melo e Cordeiro (2008, p. 29) que afirmam: "sabe-se que o magistério superior tem certo status e goza de certa parte de maior autonomia em relação ao magistério na escola básica, que aparentemente possibilita ter maiores condições de construir socialmente à profissão docente no exercício profissional". Desta forma, entendemos que ao considerar a docência no Ensino Superior como um desafio, uma conquista, os estudantes estão chamando atenção para as demandas por formação, 
qualificação e produtividade, demandas que são postas a quem ingressa no exercício docente no Ensino Superior.

A palavra "interação" expressa uma atribuição docente mais atual, que sob uma visão progressista do ensino não admite mais o professor como detentor de todo saber e como alguém que apenas transmite conteúdos, mas como alguém que na relação ensina ao aprender e aprende ao ensinar.

Conforme Tardif (2002, p. 118), o professor é um trabalhador interativo, um profissional com uma atividade essencialmente humana, baseada na relação entre pessoas. Os professores estabelecem com o seu objeto de trabalho, que são seres humanos, uma relação humana. As considerações tecidas pelo autor nos encaminham a pensar que o núcleo estruturante do ensinar está na interação, baseada na atividade conjunta entre alunos e professores. Portanto, compreender esse ato como um processo de construção compartilhada através de uma rede de comunicações é crucial para que se perceba a importância desse elemento como promotor de aprendizagens para ambos os sujeitos envolvidos no processo.

No que diz respeito aos sentidos atribuídos a "conquista" observamos uma conotação que sinaliza para a valorização atribuída aos docentes do Ensino Superior quanto ao mérito de alcançar o nível de formação requerido para este grau de ensino, assim como a inserção como profissional em instituições desse nível de ensino, representado como uma conquista, alcançada graças ao seu esforço e dedicação.

O termo "reflexão" presente nas associações dos estudantes conota a ação de refletir, de pensar criticamente sobre as questões sociais de modo amplo e restrito como expressão de um sujeito politizado que defende a transformação das estruturas macrossociais. O termo é utilizado de modo amplo para compreender e pensar a sociedade e restrito no sentido de refletir sobre as práticas individuais e coletivas dos sujeitos sociais.

Entendemos que a formação na Educação Superior pode promover a transição da consciência ingênua para a consciência crítica no que diz respeito às questões sociais e educacionais de nosso país e que esta é uma demanda socioprofissional. Os estudantes vislumbram como expectativa uma atuação docente pautada na reflexão crítica. Sabemos que, mesmo durante a ditadura militar, a universidade foi um polo de resistência e uma das grandes propulsoras do 
movimento crítico e reflexivo que incidia sobre a análise crítica dos conteúdos trabalhados e não mera recepção/reprodução do sistema vigente.

O termo "profissionalismo" ressalta uma conduta responsável, respeitosa, competente e ética, requeridas e almejadas pelos profissionais. Sua conotação é positiva, destacando o bom profissional como aquele que exerce com profissionalismo sua função.

O profissionalismo é de suma importância no Ensino Superior, porque nada é mais válido do que o professor exercer sua função com profissionalismo, sabendo entender o ser humano e acima de tudo o respeito com os discentes, manuseando uma aula clara e explicativa. (P86)

Profissionalismo, pois um bom profissional da área da educação seja de qualquer setor, tem de estar convicto do seu papel diante da sociedade, de seu grupo profissional. Atuando de forma ética e profissional. (P196)

Como podemos perceber nas justificativas, o profissionalismo ganha relevância no polo das expectativas discentes em relação à atuação docente, que de forma positiva e valorizada reconhece os atributos próprios da profissão. As justificativas acima guardam entre si algo em comum, que é o estágio intermediário de formação desses estudantes.

No campo do estudo das profissões, o termo profissionalismo é conceituado como a adesão individual à retórica e às normas da corporação, estágio onde ocorre a socialização profissional (SANTIAGO, 1994). Desta forma, atuar com profissionalismo corresponde à socialização profissional e pessoal a qual o indivíduo assimila ou adere às normas e regras do coletivo de profissionais da área, ou seja, da categoria profissional à qual pertence.

Nesse sentido, Sacristán (1991, p. 74) acrescenta:

\begin{abstract}
Uma correcta compreensão do profissionalismo docente implica relacioná-lo com todos os contextos que definem a prática educativa. O professor é responsável pela modelação da prática, mas esta é a intersecção de diferentes contextos. $O$ docente não define a prática, mas sim o papel que aí ocupa; é através da sua actuação que se difundem e concretizam as múltiplas determinações provenientes dos contextos em que participa.
\end{abstract}

Para o autor, o profissionalismo docente só pode ser compreendido quando relacionado com os contextos que definem a prática educativa. Desta forma, convém destacar que a diferenciada formação docente e o grau de ensino em que o 
profissional atua implicam no desenvolvimento do profissionalismo. Assim, situar o contexto do magistério superior é decisivo para que se determinem variações na definição profissional e na representação social da docência.

Nas análises das evocações dos estudantes, foi possível perceber que a formação docente e o grau de ensino foram determinantes para que se chegasse a uma representação social da docência ancorada em uma dimensão profissional que concebe e a representa através do domínio de conhecimentos, da condição de sujeito em constante aprendizagem, com competência para o exercício e que se compromete, se dedica e se responsabiliza por um ensino de qualidade, agindo com ética e respeito. O que nos leva a inferir, com base em Abric (2000), que a ausência de um ou mais elementos evocados pelo grupo participante da pesquisa transformaria completamente a representação que ora analisamos, assim como o contexto do objeto investigado - a docência no Ensino Superior, implica em diferentes representações sociais que são produzidas em diferentes contextos sociais e por variados grupos sociais.

Recorremos a Guerrero Séron (1996, p. 173) para reforçar o que ora afirmamos. O autor explica que:

[...] o ensino, em nosso presente sistema educativo, se estratifica em dois tipos de organizações ocupacionais: a universidade, que se organiza e se constitui como uma profissão científica e erudita, que produz e aplica seu próprio conhecimento; e o ensino básico e secundário, que se organizam e se constituem como uma profissão prática, que aplica na prática esse conhecimento convenientemente contextualizado por instâncias políticas e sociais.

Desta forma, podemos dizer que a atuação no Ensino Superior revela uma condição vinculada ao aspecto valorativo circunscrito a um tempo e a um lugar, que determina o prestígio social e a autonomia no exercício da profissão. Portanto, pressupomos que a representação social da docência pode variar de acordo com o nível de ensino, o contexto social (público ou privado) pesquisado, conforme os sujeitos ou grupos que representam um fenômeno.

Diferentemente dos estudos sobre a docência na Educação Básica (Santos, 2004; Machado; Santos, 2011), as representações sociais de docência no Ensino Superior, construídas pelos estudantes de licenciaturas, sinalizam para um movimento de construção de uma docência crítica, que rompe com os processos 
conservadores de ensino e de aprendizagem, predominantes na cultura universitária e que valoriza a dimensão da profissionalização docente, concebendo inclusive certo prestígio social aos profissionais que atuam nesse nível de ensino.

O núcleo central da representação de docência no Ensino Superior está organizado em torno dos elementos: "aprendizagem", "competência", "compromisso", “conhecimento", “dedicação", "respeito", "responsabilidade” e "ética”. Essas cognições centrais e seus respectivos sentidos configuram uma representação social de docência que incorre sobre aspectos de ordem profissional e socioafetivo que compreendem o ser docente do ponto de vista de que ensinar não é só transmitir conhecimentos, mas é, sobretudo, uma prática social comprometida com a aprendizagem dos estudantes e que demanda uma constante busca de aprendizagens e formação para atuar competentemente e qualitativamente neste nível de ensino.

A representação social de docência aqui discutida inclui propriedades de natureza qualitativa que expressam o valor simbólico e o poder associativo das cognições centrais, ou seja, suas significações e importância associada a experiências variadas dos indivíduos, assim como propriedades quantitativas representadas pela saliência das cognições e sua conexidade manifesta quantitativamente.

\section{CONSIDERAÇÕES FINAIS}

Considerando a complexidade e multidimensionalidade que envolve o ato de ensinar como prática social política e técnica, reconhecemos que as representações sociais de docência no Ensino Superior transcendem a mera instrução/transmissão de conteúdos específicos e se afiguram como algo amplo e global da ação do professor. Assim, os elementos que estruturam e organizam a representação social de docência, atribuindo a ela os sentidos e significados apresentados e discutidos neste trabalho, oferecem indícios de uma ruptura dos modelos conservadores de ensino e de aprendizagem predominantes na cultura universitária e avançam numa perspectiva que supera a docência reduzida a mera transmissão de conteúdos, para representá-la como interlocução, facilitadora das aprendizagens, demandando mobilização socioafetiva, política e crítica. A docência foi representada pelos 
estudantes como campo socioprofissional que demanda conhecimentos e competências específicas; atividade que enseja responsabilidade, compromisso, dedicação e ética. Os estudantes demonstraram que tomam seus professores como modelos de referência para as suas próprias práticas, analisando, avaliando e refletindo sobre as vivências de aprendizagem compartilhadas com os docentes formadores.

A estrutura interna dessas representações tem nos elementos aprendizagem, competência, compromisso, conhecimento, dedicação, ética, respeito e responsabilidade a sua centralidade, que, por sua vez, correspondem aos elementos mais estáveis, coerentes e consensuais da representação. Esses elementos determinam a significação e a organização interna das representações, ancorados no sistema de valores partilhados pelos membros do grupo. Os elementos centrais são, conforme aponta Abric (2000), funcionais e normativos. Nesta pesquisa o caráter funcional encontra-se representado por elementos com finalidade operatória, ou seja, referem-se aos elementos mais importantes para realização da tarefa profissional, tais como: aprendizagem, conhecimento, competência. Foi possível identificar também a dimensão normativa presente nas representações composta por elementos de ordem social e afetiva, a saber: compromisso, dedicação, ética, respeito e responsabilidade.

Inferimos que os resultados aqui comunicados constituem instrumentos de análise da docência e sua função social possibilitando compreendê-las através do olhar dos estudantes, campo pouco explorado e que merece atenção dos pesquisadores da área uma vez que a docência inexiste sem a discência e, que ambos, professores e alunos, se formam nos processos de ensino e de aprendizagem, travados em sala de aula.

\section{MÔNICA PATRÍCIA SILVA SALES}

Doutoranda em Educação pela Universidade Federal de Pernambuco (UFPE). Professora da Faculdade de Filosofia, Ciências e Letras de Caruaru (FAFICA/PE).

\section{LAÊDA BEZERRA MACHADO}


Doutora em Educação pela Universidade Federal do Rio Grande do Norte (UFRN). Professora da Universidade Federal de Pernambuco (UFPE), no Departamento de Administração Escolar e Planejamento Educacional.

\section{REFERÊNCIAS}

ABRIC, Jean-Claude. A Abordagem Estrutural das Representações Sociais. In: Estudos Interdisciplinares de representação social. 2. ed. Goiânia: AB, 2000, p. 27-38.

ALCÂNTARA, Paulo Dias de. Produção de saberes docentes por profissionais bacharéis que atuam na Docência do Ensino Superior Jurídico. 2007. Dissertação. Centro de Educação, UFPE, Recife-PE, 2007.

AMORA, Antônio Soares. Minidicionário Soares Amora da língua portuguesa. 18. ed. São Paulo: Saraiva, 2008

BEHRENS, Marilda Aparecida. A formação pedagógica e os desafios do mundo moderno. In: Docência na Universidade. Campinas, SP: Papirus, 1998, p. 57 - 68.

CUNHA, Ana Maria de Oliveira; BRITO, Taita Talamira Rodrigues; CICILLINI, Graça Aparecida. Dormi Aluno (a)... acordei professor (a): interfaces da formação para o exercício do Ensino Superior. REUNIÃO ANUAL DA ANPED, 29, 2006, CaxambuMG. Anais eletrônicos... ANPED, 2006. Disponível em: <http://www.anped.org.br>. Acesso em: 15 maio 2010.

CHIZZOTTI, Antonio. Pesquisa qualitativa em ciências humanas e sociais. Petrópolis, RJ: Vozes, 2001.

FREIRE, Paulo. Pedagogia da Autonomia: saberes necessários à prática educativa. São Paulo: Paz e Terra, 1996.

Professora sim, tia não: cartas a quem ousa ensinar. São Paulo: Editora Olho d'água,1997.

GUERRERO SERÓN, A. Manual de sociologia de la educación. Madri: Ed. Sintesis, 1996.

IBIAPINA, Ivani Maria Lopes de Melo; FERREIRA, Maria Salonilde. A formação e o desenvolvimento de conceitos de professores que atuam na Educação Superior: perspectiva de profissionalização. II ENCONTRO DE PESQUISA EM EDUCAÇÃO DA UFPI, 2002. Piauí, Anais eletrônicos. Piauí: UFPI, 2002. Disponível em: <http://www.ufpi.br/mesteduc/eventos/iiencontro/GT-2/GT-02-12.htm>. Acesso em: 24 junho 2010. 
MACHADO, Laêda B. SANTOS, Patrícia Irene dos. Profissão docente: representações sociais de professoras da educação básica. Linhas Críticas (UnB). Brasília, v.17, p.45 - 60, 2011.

MASETTO, Marcos T. Docência na Universidade. São Paulo: Papirus, 1998. $\overline{2003}$

Competência pedagógica do professor universitário. São Paulo: Summus,

MELO, Márcia M. Oliveira; CORDEIRO, Telma Santa Clara; (Org.). Formação Pedagógica e docência do professor universitário: um debate em construção. Recife: Ed. Universitária da UFPE, 2008.

OLIVEIRA, Denize Cristina de (et al.). Análise das Evocações Livres: uma Técnica de Análise Estrutural das Representações Sociais. In: Perspectivas Teóricometodológicas em representações sociais. João Pessoa: UFPB/Editora Universitária, 2005.

OLIVEIRA, José Pedro Garcia; LIMA, Maria Divina Ferreira. O sentido da prática docente segundo os estudantes do curso de Pedagogia - UFPI. II ENCONTRO DE PESQUISA EM EDUCAÇÃO DA UFPI, 2002. Piauí, Anais eletrônicos. Piauí: UFPI, 2002. Disponível em: <http://www.ufpi.br/mesteduc/eventos/iiencontro/GT-2/GT-0212.htm>. Acesso em: 24 junho 2010.

RIOS, Teresinha Azerêdo. Compreender e ensinar: por uma docência da melhor qualidade. 6. ed. São Paulo: Cortez, 2006.

. Ética e competência. 20. ed. São Paulo: Cortez, 2011.

SÁ, Celso Pereira de. Núcleo Central das Representações Sociais. Petrópolis, RJ: Vozes, 1996.

A construção do objeto de pesquisa em representações sociais. Rio de Janeiro: UdUERJ, 1998.

SACRISTÁN, J. Gimeno. Consciência e acção sobre a prática como libertação profissional dos professores. In: Profissão professor. Porto: Porto Editora, 1991, p. 61-92.

SANTIAGO, Maria Eliete. Políticas de formação e recrutamento de professores e as condições de exercer a profissão no estado de Pernambuco. Tese. Université Paris-Descartes, UPD, França, 1994.

SANTOS, Maria do Carmo. As representações sociais de gênero das professoras sobre o magistério: feminização - feminilização do campo socioprofissional. Recife, 2004. Dissertação .UFPE, Recife, 2004.

TARDIF, Maurice. Saberes Docentes e Formação Profissional. Petrópolis, RJ: Vozes, 2002. 
TARDIF, Maurice; LESSARD, Claude. O trabalho docente: elementos para uma teoria da docência como profissão de interações humanas. 5. ed. Petrópolis, RJ: Vozes, 2009.

VEIGA, IIma Passos Alencastro; ARAÚJJ, José Carlos Souza; KAPUZINIAK, Célia. Docência: uma construção ético-profissional. 2. ed. Campinas, SP: Papirus, 2005.

VĖRGES, Pierre. Conjunto de programas que permitem a análise de evocações: EVOC: manual. Versão 5. Aix en Provence: (S. n.) 2003.

A aventura de formar professores. Campinas, SP: Papirus, 2009.

ZABALZA, Miguel A. 0 ensino universitário: seu cenário e seus protagonistas. Porto Alegre: Artmed, 2004. 